Journal of Contemporary Educational Research

Research Article

\title{
The difference of Teaching Mode of Graphic Design Major in Chinese and American Universities
}

Siyao Zhang

Faculty of Arts and Design, Zhongyuan University of Technology, Zhengzhou 450007, China

\begin{abstract}
This article is based on personal visits to Louisiana State University in the United States. It analyzes and introduces the hotspots of curriculum design, training methods, learning environment, professional ability and quality training of graphic design majors in American public comprehensive universities. Analyze the teaching concepts and methods that are inspiring for the relevant design courses for our country from a personal perspective, and gain insights into the deep-seated problems in the cultivation of design innovation capabilities in China and the United States, in order to arouse everyone's reflection and further develop our country's design educational reform ideas.
\end{abstract}

Key word: Graphic design; Teaching mode; Curriculum; Chinese and American universities

Publication date: September, 2020

Publication online: 30 September, 2020

*Corresponding author: Siyao Zhang, zhangsiyao30@163.com

\section{Preface}

The School of Art and Design at Louisiana State University in the United States has five academic research directions, namely the School of Art, the School of Architecture, the School of Interior Design, the School of Landscape Architecture, and the Doctor of Cultural Design Conservation. Among them, the Bachelor of Fine Arts from the College of Art is divided into seven majors: ceramics, digital art, graphic design, painting, photography, printmaking, and sculpture. In addition, the research direction of art history is interdisciplinary, and the undergraduate program is carried out in the Faculty of Humanities and Social Sciences. The graphic design subject of the School of Art is ranked 25th among public universities in the United States (top 5\% of schools) and 5th in the South (top 3\% of schools). The college teachers are committed to excellent teaching, and professional experimenters provide intermediate and advanced level practical training, so that students become visual communicators, critical thinkers and creative problem solvers. The author has visited Louisiana State University in the United States. After a year of interviews and classroom observations, the author has a certain understanding of the teaching mode of American graphic design major. This paper attempts to analyze the characteristics of the curriculum setting of graphic design major (four-year undergraduate course) in Louisiana State University from the aspects of professional objectives and concepts, teaching content and form, teaching resources and so on, and draws some inspirations for the cultivation of innovative thinking of graphic design curriculum in Chinese universities.

\section{Curriculum}

The design and art education in the United States does not have a rigid model and system. The education system is very flexible. There is no unified management by the federal government, but each state manages itself. This is different from the establishment of Chinese art education institutions to uniformly manage design art education. With the widespread popularization of information technology, the subject knowledge system involved in graphic design in the United States has long been updated, and the professional curriculum 
has gradually involved the fields of digital media and information technology. In fact, it basically belongs to the current visual communication design major in my country. The same context. Graphic design majors generally take design courses as the core in the setting of courses, combining "general education courses", "theoretical courses" and "studio courses". The English abbreviation of Louisiana State University is LSU. The graphic design undergraduate program of the College of Art is a four-year undergraduate course, with a total of eight semesters, requiring 120 semester hours of study, and 18 semester hours of basic courses in the first year. Internships are offered in the spring, summer, and fall semesters of the third and fourth academic year. The college encourages students to participate in internships to gain more credits. The last semester of study is mainly focused on advanced thematic courses in graphic design, including a wide range of student-led research and surveys on graphic communication. The first year of study must include a total of 6 art studio basic courses, supplemented by art history and general education courses. In the first semester, all students of the School of Art need to study three core basic courses: two-dimensional design, three-dimensional design, painting and composition, as well as two courses of art history investigation and English composition. In the second semester, basic studio courses are offered, such as general beginning figure drawing, digital art I, introduction to art ceramics, introduction to painting, introduction to art sculpture, overview of modern and contemporary art, and analytical reasoning. At the end of the first year, students apply for their chosen subject through the selective admission process. The selective admission process requires the creation of two separate portfolios: one is a portfolio of basic courses, and the other is a portfolio of applications for specific subjects. Students are required to maintain a grade point average of at least $\mathrm{C}$ or above 2.0 and select the best. The second school year offers font design, abstract graphics, basic photography, art history, graphic design, color design, graphic design I, introduction to printmaking, English composition, supplemented by general courses--social science and analytical reasoning, and students enter specific design Related professional courses; Junior can choose design studio courses. The main courses include prepress production technology, art application layout, design history courses, graphic design II, digital imaging technology, studio art elective courses, supplemented by general courses---Humanities and natural sciences, students improve their practical design ability through studio courses; The fourth year of the university offers graphic design III, interactive multimedia design, studio elective courses, general education courses-humanities and natural sciences, senior graphic design, art history courses, graduation design, etc. These courses comprehensively enhance students' ability to deal with comprehensive design problems.

At the same time, in order to prepare students for graduation and entering the society, the GDSO Graphic Design Student Office specially offers pre-vocational training courses such as business. Graphic design professional studio elective courses mainly include: motion graphic design, book art, interactivity and art, graphic design synthesis, art and history of photography collections, paper art, infographic design, publication design, album cover design, etc. The studio course emphasizes the actual project or topic as the research direction. Students can conduct in-depth and specific research on a realistic topic from preliminary research, topic selection, problem raising, design deployment, design optimization, and design demonstration in groups or individually. Students are free to choose courses they are interested in and develop their design expertise.

In terms of the overall curriculum, the general courses of LSU graphic design major are mainly based on the history of art design, the basic courses are mostly based on modeling training and form composition, and the professional courses are mostly based on the application in design practice. On the whole, the content of the course is mainly concentrated in the field of modern visual communication design, and has high practicality. The time span of each course of LSU graphic design major is one semester, which is different from the common domestic several weeks of teaching to complete a professional course. The extension of the teaching time span allows teachers and students to have longer time to think and design, obtain more abundant design results, and be able to deeply understand and analyze design-related problems and provide reasonable solutions. From the perspective of curriculum content, the proportion of theoretical hours in domestic courses of the same major still dominates, and the curriculum content often lacks the practicability of market demand, which results in a lack of students' design and practical 
ability.

\section{Heuristic teaching method}

The United States is very mature in the design education concept and training model. It has a good team of teachers and teaching conditions. Through understanding, I found that their teaching methods are open and interactive, flexible and changeable and close to the society. The unique immigration culture of the United States emphasizes individualization and diversification, focuses on the cultivation of innovative thinking, encourages the development of students' personality and the realization of self-worth, so the cultivation of its design talents also emphasizes diversification and individual expression. American teachers pay special attention to the cultivation of students' personality and the interaction of teaching, so they will choose different teaching methods according to the characteristics of the course. For example, in the design history class, tests will be conducted in stages, and more lectures and independent collection of materials will be used to study related topics. The library will also arrange actual sensory experience in the library according to the telling process, and feel the charm of design prints with a century-old history. The teaching method of the studio design course teacher is more in the form of guided learning, guiding students to conduct group interactive discussions or onsite assessment of homework. Students express their opinions in the discussion, fully reflect the diversity of thinking, and obtain knowledge and inspiration from it. It is helpful to cultivate students' independent thinking ability, critical ability, expression ability and creativity. Teachers listen, ask questions, analyze and summarize. Students can boldly exchange opinions and even debate with teachers, and the classroom atmosphere is very free and casual. When students encounter specific problems in the design process, American teachers tend to provide reference books and give ideas and enlightenment, but rarely take the initiative to help students provide solutions. The final effect of student work is often not the most important, the independent innovation spirit of the designer and the process of design thinking are more valued.

American students can check the teaching process of the course and the phased tasks of the instructor from their school learning system for every course they take. If there is a problem, they can directly communicate with the teacher in the system, and the homework can be directly submitted in the system. Teachers can assign new tasks in the system at any time and upload reference materials needed for course learning. In contrast, most of the domestic student learning systems are limited to students inquiring about course information, and the function of interacting with teachers is not reflected. Chinese students are more passive in learning, relying on the "teaching" of teachers instead of expressing their design ideas and opinions. The interactive discussion and comments between students are insufficient, and students rarely hear voices from other students. Coupled with the teacher's dominant position and authority, students often regard the teacher's evaluation or suggestions as a weather vane. Although the domestic design teaching and teaching methods are changing, the views or revisions of teachers are likely to have a decisive impact on the students' work or the overall design style.

\section{Abundant teaching resources}

The teaching equipment and resources of American design colleges is also very advanced and humane. Most colleges and universities are covered by wireless networks, and students can go online anytime, anywhere, and search for information and materials through the Internet. In addition, free scanners, coinoperated photocopiers, printers and other self-service equipment can be seen everywhere in the teaching building, which provides great convenience for students. The LSU Art College has a complete laboratory and professional technician teaching. The experimental equipment is quite complete. The physical scrutiny focusing on design concepts can stimulate students' creativity. Students can use the facilities they need to create and learn without professional restrictions. For example, the design shop studio provides students with work space, hand tools, and power machinery for various uses and materials. The production factory is a new digital production laboratory that uses largescale digital manufacturing equipment to cut and shape materials such as metal, wood, and plastic to solve creative modeling design problems, where students can access the most advanced digital manufacturing equipment, Including 3D printers, laser cutting machines and $\mathrm{CNC}$ milling machines. Photography studio students can rent photography and lighting equipment and use more 3D printers and 3D scanners. $\mathrm{C} \times \mathrm{C}$ art and design studios that communicate across 
courses can learn effective communication skills for their respective professional disciplines. Most studios are equipped with dedicated instructors, and design students can use convenient resources and equipment to realize their creative intentions when doing professional creation. The Creative Center of the School of Art, featuring high-end equipment and cutting-edge technology. Teachers and students can connect to digital resources through networked laptops and mobile devices, and transfer content between workstations, studios and multiple presentation environments.

The graphic design major of LSU has set up a graphic design student office, known as GDSO, to provide professional design services for local community organizations and colleges and universities, so that students have the opportunity to gain valuable and real practical experience. If students want to join GDSO, they need to go through a selection process, including portfolio review and job interviews. Students are selected not only because of their graphic design skills, but also because of their interpersonal skills, their teamwork skills, and their passion for participation and learning. Participation in GDSO usually starts with volunteer work and then progresses to work or internships, which can earn credits. Students selected to participate in GDSO learn communication skills through interactions with other designers, customers, printing companies and professionals. They will encounter the problem-solving and cooperation situations they will encounter in future professional activities. Through these Interactive, students gain firsthand professional graphic design practical experience.

LSU has an independent art museum with abundant art resources. The museum seeks to enrich and inspire artistic creativity through collection, exhibition, preservation and education, as a cultural and intellectual resource for universities and local communities. Oncampus and off-campus galleries, such as Foster Gallery and Glassell Gallery, provide a strong schedule and showcase the work of local and national artists. These galleries provide students with opportunities to showcase their works. The teachers of LSU School of Design are good at making use of these resources to carry out "art criticism" and conduct lectures and research directly facing the work itself, and participate in various art seminars with students, which greatly enriches the teaching content and expands with an academic perspective, lead everyone to think and explore research issues in real objects. LSU has a special collection library, Hill Memorial Library, which provides research centers for humanities, social sciences and fine arts. The special collection includes more than 200,000 published works and natural history collections, more than 10 million manuscripts, 200,000 historical photographs, 16,000 rolls of newspaper microfilms, hundreds of oral histories and various other materials for research. There are many opportunities for art college students to travel and study abroad, including programs in Ireland, Florence, London and New York. The impact of various cultures and thinking patterns in the learning process will bring inspiration and wisdom to each participant, which cannot be replaced by local learning in the university.

The teaching equipment and laboratory environment of domestic design colleges have also been gradually improved. However, the experimental equipment of many colleges and universities is only open during the relevant professional courses. If students use it outside of class, strict approval is required. When some laboratories are open, there are still professional restrictions and insufficient equipment resource sharing, which brings great inconvenience to students' design creation. The inter-professional experimental space is very conducive to cultivating students' interdisciplinary thinking ability and creative thinking, provides more choices and possibilities for students' creation, and fully reflects the unity of art and technology. How to optimize experimental teaching conditions and improve the management of experimental equipment is a problem worthy of consideration by domestic design teaching staff.

\section{Conclusion}

The development of design education in the United States predates China. The United States and China have formed different styles of teaching concepts and training models due to their different humanistic backgrounds. Graphic design education in American colleges and universities is influenced by American business culture. It advocates the combination of creativity, practicality and artistry, focuses on the integration of social platforms and resources, flexible and changeable teaching methods, and emphasizes the supporting role of high technology in design and cross-industry innovative thinking. The evaluation 
of American students' work also pays attention to details, practicality and commerciality. China's graphic design education is transforming to the direction of visual communication design, integrating traditional graphic design and digital media, and has its own characteristics. Because design itself has complex social practice attributes, it is easier to develop design education in a broad academic field of vision, so that teaching and application can play a joint role, so that students' comprehensive innovation ability can be cultivated and improved. Understanding the American design education model through speculation is helpful to develop design education reform ideas that suit my country's national conditions. By understanding the training model of graphic design professionals in American colleges and universities, studying and drawing on their advanced methods and experience, striving to introduce excellent educational concepts and school-running ideas, and adopting teaching methods that are more in line with the characteristics of the design discipline, to stimulate students'enthusiasm for learning, These experiences have brought reference and enlightenment to the design teaching of my country's colleges and universities, and explored ways to cultivate innovative design thinking capabilities that are more in line with the characteristics of design education in my country.

\section{Reference}

[1] Louisiana State University. https://design.lsu.edu/

[2] Liu H. A Comparative Analysis of Design Education Models between China and the United States: Taking Virginia Tech as an Example [J]. Decoration, 2010(10).

[3] Xiong TT, Wei W. A Comparative Study on the Curriculum of Graphic Design (Visual Communication Design) between China and the United States: Taking the Graphic Design Major of Auburn University as an example[J]. Beauty and Times (Part 1), 2013(06).

[4] Li Z. Research on Curriculum Setting of Visual Communication Design Major in my country [D]. Wuhan University, 2016. 